\title{
Proposed Plan to Investigate the Impact of Amniotic Fluid Index on Pregnancy Outcome at Selected Obstetrics \& Gynecology Clinics, Jeddah, Saudi Arabia
}

\author{
Dr. Huda Shali A. Aljedaani \\ Ibn Sina College, Jeddah
}

\begin{abstract}
Background: Amniotic fluid is vital to the well fetus. It cushions the fetus from injury, helps to prevent compression of the umbilical cord, and allows room for it to move and grow. The current study amid at introducing a Proposed Plan to Investigate the Impact of Amniotic Fluid Index on Pregnancy Outcome at Selected Obstetrics \& Gynecology Clinics, Jeddah, Saudi Arabia. The purposes in its utilization are evaluation of maternal serum interleukin-6 (il-6) as an early marker of subclinical chorioamnionitis in patients with preterm premature rupture of membranes. Hoping to improve maternal and neonatal outcome in PPROM and to bring about changes in management strategies in PPROM. Objective: To provide a framework of Proposed Plan to Investigate the Impact of Amniotic Fluid Index on Pregnancy Outcome at Selected Obstetrics \& Gynecology Clinics, Jeddah, Saudi Arabia. Method: An experimental research design is proposed to be utilized in the current study in which the participants will be divided into two groups a study group presenting with PPROM between 24 and 34 weeks gestation and a control group of healthy pregnant women without PPROM (matched for age, parity, and gestational age. Serum IL-6 levels will be determined by solid-phase sandwich enzyme-linked immunosorbent assay. Results: This study finding will include the data related to evaluation the clinical usefulness of maternal serum IL-6 as early marker for detection of subclinical chorioamnionitis in patients with preterm premature rupture of membranes. Secondly to compare interleukin 6 with total leukocyte count and $C$ reactive protein as a method for earlier detection of subclinical chorioamnionitis in patients with preterm premature rupture of membranes. Conclusions: The current study results aiming to reveal the data beyond the achievement the objectives Assessment of need for additional markers in the maternal serum, simpler and less invasive than amniocentesis to predict intrauterine infection. Secondly, Early diagnosis of subclinical infection and inflammation that may therefore aid clinicians to institute interventions focusing on adverse outcomes. Finally, Subjective and objective assessment of early onset of complications and/or side effects.
\end{abstract}

Keywords: Proposed Plan, Amniotic Fluid Index \& Pregnancy Outcome

\section{Introduction}

According to Hulter et al., (2010), an antepartum or intrapartum amniotic fluid index of $\leq 5.0 \mathrm{~cm}$ is associated with a significantly increased risk of cesarean delivery for fetal distress and a low Apgar score at 5 minutes. There are few reports linking amniotic fluid index and neonatal acidosis, the only objective assessment of fetal well-being. A multicenter study with sufficient power should be undertaken to demonstrate that a low amniotic fluid index is associated with an umbilical arterial $\mathrm{pH}<7.00$. With the advent of realtime ultrasonography, assessment of amniotic fluid has been possible, resulting in earlier recognition of abnormal conditions and possible intervention. Since, these disorders of liquor amine has a significant impact on pregnancy and fetus, it prompted us to carry out this study with sincere efforts to find out its effect on pregnancy outcome

Premature rupture of membranes is defined as spontaneous membrane rupture that occurs before the onset of labor. When membrane rupture occurs before 37 weeks gestation it is referred to as Preterm Premature rupture of membranes (PPROM). Noor, et al., (2007).According to Nava, et al., (2003), premature rupture of membranes continues to be a leading cause of neonatal morbidity and mortality. It occurs in approximately $2-8 \%$ of all pregnancies but it is associated with $20 \%$ of per-natal deaths. Complications include maternal and fetal infection, preterm labor, asphyxia and if earlier in pregnancy pulmonary hypoplasia and anatomic distortion as a result of amniotic bands.

Furthermore Goldenberg, Culhane\& Romero, (2008), mentioned that subclinical intrauterine infection has been implicated as a major etiological factor in the pathogenesis and subsequent morbidity associated with PPROM, but once clinical chorioamnionitis is present, there is a fourfold increase in neonatal mortality. Early infection is not reliably predicted by commonly used laboratory variables such as erythrocyte sedimentation rate, white blood cell count, neutrophil count, or vaginal bacterial culture. Clinical signs such as fever and feto-maternal tachycardia usually appear late. (Trochez, Smith \& Lamont, 2007). To the greatest of our understanding, current study amid at introducing a Proposed Plan to Investigate the Impact of Amniotic Fluid Index on Pregnancy Outcome at Selected Obstetrics \& Gynecology Clinics, Jeddah, Saudi Arabia. Consequently, conducted this study will assist in providing a framework for evaluation the clinical usefulness of maternal serum IL-6 as early marker for detection of subclinical chorioamnionitis in patients with preterm premature rupture of membranes. Secondly to compare interleukin 6 with total leukocyte count and $\mathrm{C}$ reactive protein as a method for earlier detection of subclinical chorioamnionitis in patients with preterm premature rupture of membranes. 


\section{Participants and Methods}

Gathered data will be processed using suitable statistical package. Quantitative data will be expressed as means \pm SD while qualitative data will be expressed as numbers and percentages $(\%)$. Student $t$ test will be used to test significance of difference for quantitative variables and Chi Square will be used to test significance of difference for qualitative variables. A probability value $(p$-value $)<0.05$ will be considered statistically significant. Other statistical tools may be used when appropriate and applicable. Data will be analyzed and appropriately presented in tables and figures.

This is a case-control study enrolled persons will be divided into two groups a study group presenting with PPROM between 24 and 34 weeks gestation and a control group of healthy pregnant women without PPROM (matched for age, parity, and gestational age. Serum IL-6 levels will be determined by solid-phase sandwich enzyme-linked immunosorbent assay. A total of 54 women will be recruited for the study. Patients will be divided into two equal groups, 27 in each. Group A (case group): consisted of 27 patients at 24-34 weeks' gestation with preterm PROM without any clinical chorioamnionitis at time of hospitalization and inclusion in the study .Group B (control group) : consisted of 27 women at 24-34 weeks' gestation without ROM.

\section{Inclusion Criteria}

Selection of patients:-Diagnosis of PPROM will (24-34

weeks gestation) based on:

- History of sudden gush of clear fluid from the vagina.

- Presence of pool of fluid in posterior fornix during sterile speculum examination.

- Escape of amniotic fluid from cervix on coughing or applying abdominal pressure.

- Positive nitrazine test.

- Positive fern test.

\section{Exclusion Criteria:}

- Patient exceed 34 weeks of gestation and before 24 weeks of gestation

- Evident clinical chorioamnionitis.

- Patients with pregnancy-induced hypertension.

- Antepartum hemorrhage.

- Multiple gestation.

- Polyhydramnious.

- Immunological disorders.

- Medical disorders such as anemia, heart disease, hypertension, and diabetes mellitus.

- Those with evidence of any other infection such as urinary tract infections will be excluded from the study.

\section{Every subject will be subjected to:}

- Clinical assessment.

- Complete history to diagnose preterm PROM and to exclude any symptoms suggestive of infection.

- General examination of pulse and temperature to exclude any signs of infection.
- Abdominal examination to exclude any signs of infection and feel uterine contractions or tenderness.

- Sterile speculum examination to diagnose preterm PROM and to exclude labor.

Laboratory assessment: withdrawal of $5 \mathrm{ml}$ venous sample for measurement of:

- Complete blood count.

- C reactive protein .

-IL-6 estimation Sera will be separated and immediately stored at $-70^{\circ} \mathrm{C}$ until they will batch analyzed. Single blood samples will be taken for assessing serum IL-6 levels from the control group while three blood samples (at the time of admission, at $48 \mathrm{hr}$, and on day 7 of admission or onset of labor whichever was earlier) will be taken from PPROM group. Serum IL-6 levels will be determined by solid-phase sandwich enzyme linked immunosorbent assay.

\section{Conservative inpatient management consisting of:}

- Antibiotics in form of erythromycin $500 \mathrm{mg}$ tablet orally every 6 hours for 7 days. 12

- Corticosteroids in the form of dexamethasone $8 \mathrm{mg}$ ampoule intramuscular injection every 8 hours for 3 doses.

- Temperature chart.

- Tocolysis will not be given.

- Frequent observation of maternal and fetal wellbeing until termination of pregnancy is decided.

- Termination of pregnancy will be done when:12

- Delivery should be considered at 34 weeks of gestation. Where expectant management is considered beyond this gestation, women should be informed of the increased risk of chorioamnionitis and the decreased risk of respiratory problems in the neonate.

- Appearance of evidence of clinical chorioamnionitis, accidental hemorrhage or fetal distress.

- Spontaneous onset of labor pains.

After delivery, the followings will be assessed:

- Maternal outcome:

- Occurrence of puerperal sepsis.

- Occurrence of wound infection.

- Fetal outcome:

- APGAR score at 1 and 5 minutes.

- Fetal weight.

- Need for NICU admission.

Occurrence of Neonatal Complications:

- TTN

- RDS.

- Deep jaundice

- Histopathological examination of placenta and membranes a marker of histological chorioamnionitis.

\section{Sample Size Estimation}

The sample size is calculated from this equation: 


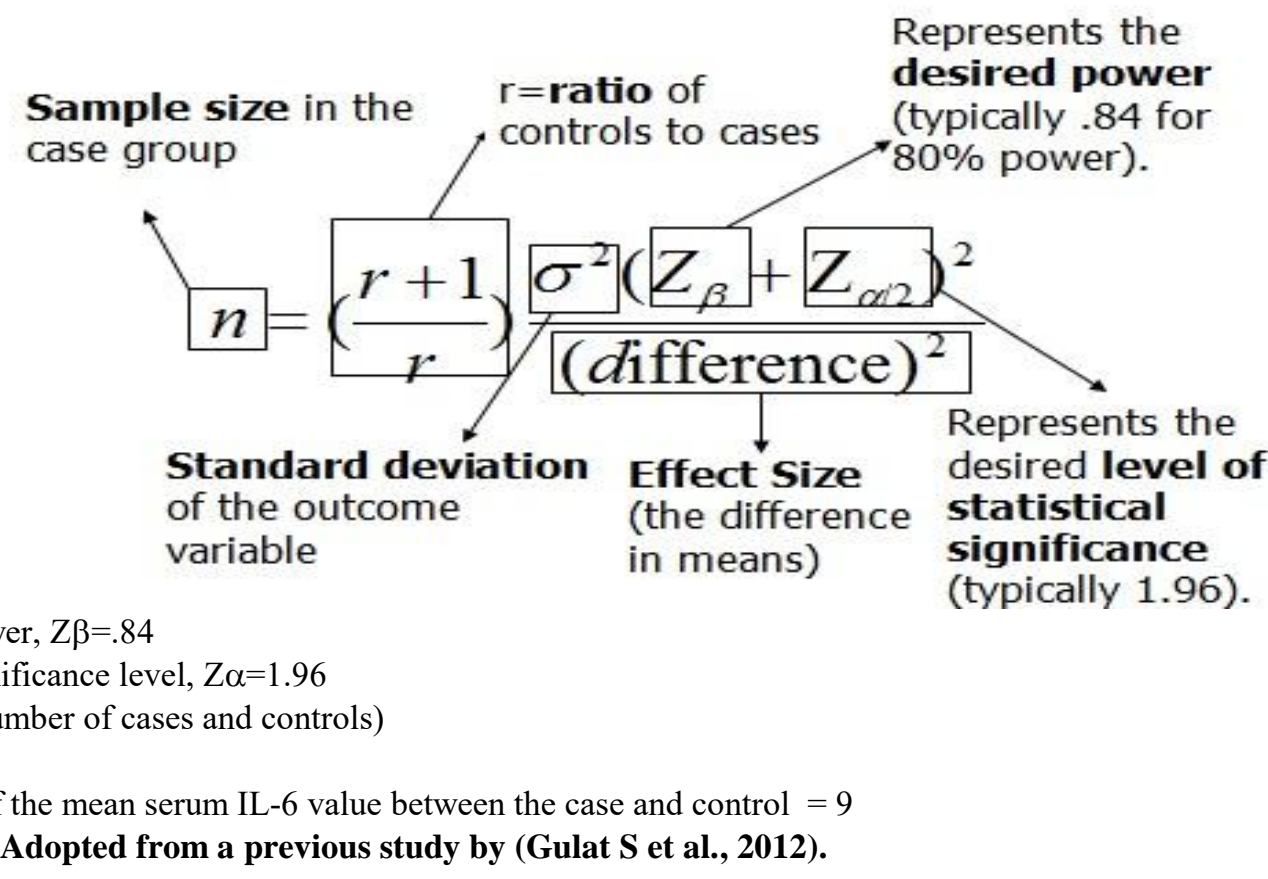

\section{Discussion}

Various studies have shown that chorioamnionitis leads to a rise of several cytokines in amniotic fluid, fetal cord blood, and maternal serum. This study findings congruent with the result of the research carried out by Resnick, et al., (2002), who focused on Calciotropic hormones in pre-eclampsia: a renewal of interest, it was reported that Limited sun exposure is the main reason beyond vitamin d deficiency among the pregnant women. On the other hand, the study carried by Seely, (2007), focused on Chronic continuous PTH infusion results in hypertension in normal subjects., showed that only $96 \%$ of the studied sample from the pregnant women were had vitamin D deficiency due to limited sun exposure and Mal-absorptive syndromes (cystic fibrosis, cholestatic liver disease, inflammatory bowel disease, short gut syndrome), which constant with the current study results.

In cases of intrauterine infection, cytokines produced within the uterine cavity first mount a local inflammatory response and then reach the maternal circulation and the liver to stimulate the synthesis of C-reactive protein (CRP) by hepatocytes or bone marrow targets to induce leukocytosis. Hence, rise in cytokines occurs earlier than that of CRP. IL-6 is a very well-known infection/inflammation marker and it is found to be significantly elevated in maternal serum, amniotic fluid and vaginal secretion in preterm labour and PPROM patients

This cytokine as well as other pro-inflammatory markers have been studied to predict the interval to delivery and maternal and neonatal outcomes. Amniotic fluid IL-6 levels have been proposed as marker for evolving chorioamnionitis but it requires amniocentesis, which is an invasive procedure. A simpler and less invasive method of measuring IL-6.cytokine in maternal serum would be useful for the identification of asymptomatic intrauterine infections in patients with PPROM. In addition to the parameters routinely used for the detection of infection (CRP, leukocytosis, body temperature, and fetal heart rate), there is a need to investigate whether serum IL-6 levels can supplement or even replace routine inflammatory parameters in diagnosis of subclinical chorioamnionitis and help to decide timely delivery of the fetus.

However clinical signs of infection are subtle and usually not present in early patients. Currently there are no reliable clinical markers to adequately indicate impending intrauterine infection in patients with premature rupture of membranes so a more sensitive test which is capable of identifying intrauterine infection soon after it occurs is needed.

The anticipated benefits: Improving pregnancy outcome in patients with subclinical chorioamnionitis .Furthermore , The potential risks: no suspected risk. As well as, condut follow up such as ongoing monitoring of possible side effects.Each participant has the right to abstain or withdraw at any time without any reprisals.

\section{Acknowledgements}

Appreciation is hereby extended to all the participants and administrators staff at the selected setting-Saudi Arabia.

\section{References}

[1] Noor S, Nazar AF, Bashir R, Sultana R (2007): Prevalence of PPROM and its outcome. J Ayub Med Coll Abbottabad; 19:14-17.

[2] Nava Flores J, Enríquez Miranda MC, HernándezValencia M (2003): Maternal and fetal morbidity in patients with premature rupture of the membrane after 27-week gestation. Causes and costs. GinecolObstet Mex.;71:343-8.

[3] Mc Parland PC, Bell SC, (2004): The fetal membranes and mechanism underlying their labour associated and

\section{Volume 6 Issue 1, January 2017




\section{International Journal of Science and Research (IJSR) \\ ISSN (Online): 2319-7064}

Index Copernicus Value (2015): 78.96 | Impact Factor (2015): 6.391

pre-labour rupture during pregnancy. Fetal Matern Med Rev 15: 73:108.

[4] Goldenberg RL, Culhane JF, Iams JD, Romero R( 2008): Epidemiology and causes of preterm birth. Lancet; 371:75-84.

[5] Trochez-Martinez RD, Smith P, Lamont RF( 2007): Use of C-reactive protein as a predictor of chorioamnionitis in preterm prelabour rupture of membranes: a systematic review. Br J Obstet Gynaecol; 114:796-801.

[6] Murtha AP, Sinclair T, Hauser ER, Heine RP( 2007): Maternal serum cytokines in preterm premature rupture of membranes. Obstet Gynecol; 109:121-127.

[7] Goldberg RL, Hauth JC, Andrews WW(2000): Intrauterine infection and preterm delivery. $\mathrm{N}$ Engl $\mathrm{J}$ Med; 342:1500-1507.

[8] Holst RM, Laurini R, Jacobsson B, Samuelsson E et al., (2007): Expression of cytokines and chemokines in cervical and amniotic fluid : relationship to histological chorioamnionitis.

[9] Sorokin Y, Romero R, Mele L, Wapner RJ, et al.,(2010): Maternal serum interleukin-6,C-reactive protein, and matrix metalloproteinase- 9 concentrations as risk factors for preterm birth $<32$ weeks and adverse neonatal outcomes. Am J Perinatol; 27:631-640.

[10] Murtha AP, Greig PC, Jimmerson CE, Herbert WN(1998): Maternal serum interleukin-6 concentration as a marker for impending preterm delivery. Obstetrics \& Gynecology. Feb;91 (2):161-4.

[11] Shobokshi A and Shaarawy M (2002): Maternal serum and amniotic fluid cytokine in patients with premature rupture of membranes with and without intrauterine infection. Int J Gynaecol Obstet; 79:209.

[12] RCOG Green-top Guideline No. 44

[13] http://www.stanford.edu/ kcobb/hrp261/lecture8.ppt

[14] Gulat S,Bhatngar S,Raghunandan C, Bhattacharjee $\mathrm{J}(2012)$ : interleukin-6 as a predictor of subclinical chorioamnionitis in patients with preterm premature rupture of membranes.76:265-240.

[15] Taufield PA, et al. Hypocalciuria in pre-eclampsia. N Engl J Med. 2002;316:715-8. [PubMed]

[16] Hulter HN, Melby JC, Peterson JC, Cooke CR. Chronic continuous $\mathrm{PTH}$ infusion results in hypertension in normal subjects. J Clin Hypertens. 2001;2:360-70. [PubMed]

[17] Resnick LM, Laragh JH, Sealey JE, Alderman MH. Divalent cations in essential hypertension. Relations between serum ionized calcium, magnesium, and plasma renin activity. N Engl J Med. 2002;309:888-.[PubMed]

[18] Seely EW. Calciotropic hormones in pre-eclampsia: a renewal of interest. J Clin Endocrinol Metab. 2007;92:3402-3. [PubMed]

[19] Bodnar LM, Catov JM, Simhan HN, Holick MF, Powers RW, Roberts JM. Maternal vitamin D deficiency increases the risk of preeclampsia. J Clin Endocrinol Metab. 2007;92:3517-22. [PMC free article][PubMed]

[20] Olsen SF, Secher NJ. A possible preventive effect of low-dose fish oil on early delivery and pre-eclampsia: indications from a 50-year-old controlled trial. $\mathrm{Br} \mathrm{J}$ Nutr. 2005;64:599-609. [PubMed]

[21] Marya RK, Rathee S, Manrow M. Effect of calcium and vitamin $\mathrm{D}$ supplementation on toxaemia of pregnancy. Gynecol Obstet Invest. 2001;24:38-42. [PubMed]
[22] Levine RJ, Hauth JC, Curet LB, et al. Trial of calcium to prevent preeclampsia. N Engl J Med. 2000;337:6976. [PubMed]

[23] Villar J, Abdel-Aleem H, Merialdi M, et al. World Health Organization randomized trial of calcium supplementation among low calcium intake pregnant women. Am J Obstet Gynecol. 2006;194:63949.[PubMed]

[24] Sabour H, Hossein-Nezhad A, Maghbooli Z, Madani F, Mir E, Larijani B. Relationship between pregnancy outcomes and maternal vitamin D and calcium intake: a cross-sectional study. GynecolEndocrinol. 2006;22:585-9. [PubMed]

[25] Scholl TO, Chen X. Vitamin D intake during pregnancy: association with maternal characteristics and infant birth weight. Early Hum Dev. 2009;85:231-. [PubMed]

[26] Brooke OG, Wood C. Growth in British Asians: longitudinal data in the first year. J Hum Nutr. 1980;34:355-9. [PubMed]

[27] Brooke OG, Brown IR, Cleeve HJ, Sood A Observations on the vitamin D state of pregnant Asian women in London. BJOG. 1981;88:18-26. [PubMed]

[28] Brooke OG, Butters F, Wood C. Intrauterine vitamin D nutrition and postnatal growth in Asian infants. BMJ (Clin Res Ed) 1981;283:1024. [PMC free article] [PubMed]

[29] Mallet E, Gügi B, Brunelle P, Hénocq A, Basuyau JP, Lemeur H. Vitamin D supplementation in pregnancy: a controlled trial of two methods. Obstet Gynecol. 2000;68:300-4. [PubMed]

[30] Mannion CA, Gray-Donald K, Koski KG. Association of low intake of milk and vitamin D during pregnancy with decreased birth weight. CMAJ. 2006;174:1273-7. [PMC free article] [PubMed]

[31] Olsen SF, Halldorsson TI, Willett WC, et al. Milk consumption during pregnancy is associated with increased infant size at birth: prospective cohort study. Am J Clin Nutr. 2007;86:1104-10. [PubMed]

[32] Russell JG, Hill LF. True fetal rickets. Br J Radiol. 1974; 47:732-4. [PubMed]

[33] Orbak Z, Karacan M, Doneray H, Karakel-leoglu C. Congenital rickets presenting with hypocalcaemic seizures. West Indian Med J. 2007;56:364-7. [PubMed]

[34] Specker BL, Ho ML, Oestreich A, et al. Prospective study of vitamin D supplementation and rickets in China. J Pediatr. 2003;120:733-9. [PubMed]

[35] Weiler H, Fitzpatrick-Wong S, Veitch R, et al. Vitamin $\mathrm{D}$ deficiency and whole-body and femur bone mass relative to weight in healthy newborns. CMAJ. 2005;172:757-61. [PMC free article] [PubMed]

[36] Javaid MK, Crozier SR, Harvey NC, et al. Maternal vitamin $\mathrm{D}$ status during pregnancy and childhood bone mass at age 9 years: a longitudinal study. Lancet. 2006;367:36-43. [PubMed]

[37] Reif S, Katzir Y, Eisenberg Z, Weisman Y. Serum 25hydroxyvitamin D levels in congenital craniotabes. Acta Paediatr Scand. 1988;77:167-8. [PubMed]

[38] Congdon P, Horsman A, Kirby PA, Dibble J, Bashir T. Mineral content of the forearms of babies born to Asian and white mothers. BMJ (Clin Res Ed) 1983;286:12335. [PMC free article] [PubMed]

\section{Volume 6 Issue 1, January 2017




\section{International Journal of Science and Research (IJSR) \\ ISSN (Online): 2319-7064}

Index Copernicus Value (2015): 78.96 Impact Factor (2015): 6.391

[39] Hillman LS, Haddad JG. Human perinatal vitamin D metabolism: I, 25-hydroxyvitamin $\mathrm{D}$ in maternal and cord blood. J Pediatr. 1974;84:742-9. [PubMed]

[40] Ala-Houhala M. 25-Hydroxyvitamin D levels during breast-feeding with or without maternal or infantile supplementation of vitamin D. J Pediatr Gastroenterol Nutr. 1985;4:220-6. [PubMed]

[41] Salle BL, Glorieux FH, Lapillone A. Vitamin D status in breastfed term babies. Acta Paediatr. 1998;87:726-7. [PubMed]

[42] Hollis BW, Roos BA, Draper HH, Lambert PW. Vitamin D and its metabolites in human and bovine milk. J Nutr. 1981;111:1240-8. [PubMed]

[43] Camadoo L, Tibbott R, Isaza F. Maternal vitamin D deficiency associated with neonatal hypocalcaemic convulsions. Nutr J. 2007;6:23. [PMC free article] [PubMed]

[44] Oki J, Takedatsu M, Itoh J, Yano K, Cho K, Okuno A. Hypocalcemic focal seizures in a one-month-old infant of a mother with a low circulating level of vitamin D. Brain Dev. 1991;13:132-4. [PubMed]

[45] Maiya S, Sullivan I, Allgroove J, et al. Hypocalcaemia and vitamin D deficiency: an important, but preventable, cause of life-threatening infant heart failure. Heart. 2008;94:581-4. [PubMed]

[46] Kosecik M, Ertas T. Dilated cardiomyopathy due to nutritional vitamin D deficiency rickets. Pediatr Int. 2007;49:397-9. [PubMed]

[47] Ward LM, Gaboury I, Ladhani M, Zlotkin S. Vitamin D-deficiency rickets among children in Canada. CMAJ. 2007;177:161-6. [PMC free article] [PubMed]

[48] Ladhani S, Srinivasan L, Buchanan C, All-grove J. Presentation of vitamin D deficiency. Arch Dis Child. 2004;89:781-4. [PMC free article] [PubMed]

[49] Dawodu A, Tsang R. Vitamin D deficiency and rickets: possible role of maternal vitamin D deficiency. Ann Trop Paediatr. 2007;27:319. [PubMed]

[50] Hollis BW, Wagner CL. Vitamin D requirements during lactation: high-dose maternal supplementation as therapy to prevent hypovitaminosis $\mathrm{D}$ for both the mother and the nursing infant. Am J Clin Nutr. 2004;80:1752S-8S. [PubMed]

[51]Litonjua AA, Weiss ST. Is vitamin D deficiency to blame for the asthma epidemic? J Allergy Clin Immunol. 2007;120:1031-5. [PubMed]

[52] Wittke A, Chang A, Froicu M, et al. Vitamin D receptor expression by the lung micro-environment is required for maximal induction of lung inflammation. Arch Biochem Biophys. 2007;460:306-24.[PMC free article] [PubMed]

[53] Poon AH, Laprise C, Lemire M, et al. Association of vitamin $\mathrm{D}$ receptor genetic variants with susceptibility to asthma and atopy. Am J Respir Crit Care Med. 2004;170:967-73. [PubMed]

[54] Raby BA, Lazarus R, Silverman EK, et al. Association of vitamin $\mathrm{D}$ receptor gene polymorphisms with childhood and adult asthma. Am J Respir Crit Care Med. 2004;170:1057-65. [PubMed]

[55] Cantorna MT, Zhu Y, Froicu M, Wittke A. Vitamin D status, 1,25-dihydroxyvitamin D3, and the immune system. Am J Clin Nutr. 2004;80:1717S-20S. [PubMed]
[56] Cantorna MT. Vitamin D and its role in immunology: multiple sclerosis, and inflammatory bowel disease. Prog Biophys Mol Biol. 2006;92:60-4. [PubMed]

[57] Banerjee A, Damera G, Bhandare R, et al. Vitamin D and glucocorticoids differentially modulate chemokine expression in human airway smooth muscle cells. $\mathrm{Br} \mathrm{J}$ Pharmacol. 2008;155:84-92.[PMC free article] [PubMed]

[58] Song Y, Qi H, Wu C. Effect of 1,25-(OH)2D3 (a vitamin $\mathrm{D}$ analogue) on passively sensitized human airway smooth muscle cells. Respirology. 2007;12:48694. [PubMed]

[59] Nguyen M, Trubert CL, Rizk-Rabin M, et al. 1,25Dihydroxyvitamin D3 and fetal lung maturation: immunogold detection of VDR expression in pneumocytes type II cells and effect on fructose 1,6 bisphosphatase. J Steroid Biochem Mol Biol. 2004;8990:93-7. [PubMed]

[60] Camargo CA, Jr, Rifas-Shiman SL, Litonjua AA, et al. Maternal intake of vitamin D during pregnancy and risk of recurrent wheeze in children at $3 \mathrm{y}$ of age. Am J Clin Nutr. 2007;85:788-95. [PMC free article][PubMed] 